\title{
Güzel Sanatlar Eğitimi Bölümü Öğrencilerinin Bazı Değişkenlere Göre Akademik Motivasyonları ile Akademik Başarıları Arasın- daki İlişkinin İncelenmesi*
}

\author{
A Study on Department of Fine Arts Education Students' Level of Aca- \\ demic Motivation according to Some Variables the Relation between \\ Their Academic Motivation and Academic Success
}

DOI $=10.17556 / j$ jef.62310

\section{MelihaYILMAZ $^{* *}$, OrhanTAŞKESEN ${ }^{* * *}$, Selma TAŞKESEN ${ }^{* * * * *}$ \\ Özet}

Bu çalışmanın amacı, Eğitim Fakültesi Güzel Sanatlar Eğitimi Bölümü öğrencilerinin bazı değişkenlere göre (Anabilim Dalı, sınıf, cinsiyet) akademik motivasyon düzey farkını, ayrıca akademik motivasyonları ile akademik başarıları arasındaki ilişkiyi araştırmaktır. Araştırma güzel sanatlar eğitimi bölümünden toplam 219 öğrenci (Resim Öğretmenliği 123, müzik öğretmenliği 96) ile yürütülmüştür. Araştırmada Akademik Motivasyon Ölçeği (AMÖ) ve nicel araştırma yöntemlerinden ilişkisel tarama yöntemi kullanılmıştır. Anabilim dalı ve cinsiyet değişkenine göre akademik motivasyonu karşılaştırmak için Mann Whitney U, sınıflara göre akademik motivasyon farkını test etmek için ise, Kruskal Wallis H testi kullanılmıştır. Araştırmada akademik motivasyon ve akademik başarı arasındaki ilişki ise, sperman korelasyon testi ile test edilmiştir.

Araştırmada ana bilim dalı, cinsiyet ve sınıf değişkenine göre gruplar arasında akademik motivasyonfarkına rastlanmıştır. Akademik motivasyon ve akademik başarı arasında anlamlı bir ilişki olmadığı bulgusuna ulaşılmıştır.

Anahtar Sözcük:GüzelSanatlarEğitimi， Resim-İşveMüziköğretmenliği, akademikmotivasyon, akademikbaşarı

\section{Abstract}

Aim of this study is to examine Faculty of Education Department of Fine Arts Students' level of academic motivation difference according to some variables

*Bu makale "Cumhuriyetin Işı̆̆ında Yükseköğretimde Sanat Eğitimi Uluslararası Sempozyumu"nda sözlü bildiri olarak sunulmuş, tavsiyeler doğrultusunda kısmi değişiklikler yapılmıştir.

*** Doç. Dr., Gazi Ün., mel.yilmaz0637@gmail.com

*** Doç.Dr.,Erzincan Ün., orhantaskesen@gmail.com

**** Öğrt. slmtsksn@gmail.com 
(department, grade, gender) and to research the relation between their academic motivation and academic success. In this sense, academic motivation scale (AMS), consisting of a motivation, internal motivation and external motivation, was applied to 219 fine arts teacher candidates (123 arts teaching, 96 music teaching).Relational screening model, one of the quantitative research methods, was used in the study. Mann Whitney U. test was used to compare the academic motivation according to department and gender variables also Kruskal Wallis $\mathrm{H}$ test was applied to test the academic motivation difference. In the study, Sperman correlation test was also used to test the relation between academic motivation and academic success.

Significant difference was found in teacher candidates' level of academic motivation according to department, gender and grade variables. therewasnosignificantdifference in the relation between the academic motivation and academic success.

Keywords:Fine Arts Education, Arts and Music Teaching, academic motivation, academic success

\section{Giriş}

Nitelikli insan yetiştirme ülkelerin en önde gelen arzu ve gereksinimleri arasında yer alır. Nitelikli insan yetiştirme iyi kurgulanmış eğitim politikaları ve stratejileri ile mümkündür. Eğitim politikalarının süreç içinde uygulayıcılarından biri olarak öğretmenler, bu süreçte en önemli rolü oynar. Buna bağlı olarak öğretmen yetiştiren kurumların sorumluluk ve görevleri günden güne artmakta ve güncellenmektedir. Eğitimin niteliğini belirleyen en onemli unsurlardan biri de öğrencilerin akademik başarısıdır. Öğretmen yetiştiren kurumlar öğretmen adaylarının girdikleri mesleki sınavlar ve yapılan araştırmalarla öğrencilerin başarıları üzerinden kendi kurumsal başarıları hakkında bilgi sahibi olmaktadırlar. Araştırmalara göre öğrenci başarısını etkileyen bir çok faktör mevcuttur. Örneğin Karagüven'e göre (2012) bu faktörler; öğrencinin kendi kendini etkin bir şekilde yönlendirmesi, planlama ve izleme yeteneği, kendi davranış, zihin ve öğrenme stratejilerini değerlendirebilmesi gibi faktörlerdir ve aynı zamanda öğrencinin yeni ögrenme stratejilerini de etkin olarak kullanmaya motive olması gerekir. Yine bir çok araştırma (Arıc1, 2007; Eymur ve Geban, 2011; Aktan, 2012; Kruskar ve diğ., 2012 ;Alemdağ, Öncü, Y1lmaz 2014) akademik motivasyonun bu faktörlerden biri olduğunu göstermiştir. Karagüven (2012) akademik başarıyı yükseltmeyi amaçlayan her eğitimcinin zaman zaman öğrencilerinin motivasyonu ile ilgilenmek durumunda olduğunu ve motivasyon sorunlarının akademik başarıyı etkileyen önemli ve güncel bir problem alanı olarak gözlendiğini 
ifade etmektedir. Motivasyon kelimesi " . 1. Harekete getirme, harekete sevk etme. 2. İtici kuvvet, harekete yöneltici içsel güç anlamlarına gelen, insanın hedef için güdülenmesi olarak tanımlanan bir sözcüktür. (Türk Dil Kurumu [TDK], 2011). Y1lmaz (2010) bireyin çeşitli yönlerden olgunlaşma düzeyi, önceki öğrenmeleri, genel sağlık durumu yeterli düzeyde olduğu kabul edildiğinde, hazır bulunuşluk açısından en önemli olanın "istek duyma" yani motivasyon olduğunu, motivasyonun bireyi yalnızca bir davranışı yapmaya istekli hale getirmek ve davranışın enerji düzeyini belirlemekle kalmayıp, o davranışın devamını da sağladığını belirtmiştir. Motivasyon eğitim alanında bir çok yönü ile araştırılmıştır. Bu araştırmalar genellikle motivasyonun akademik performansa, başarıya etkilerini araştıran (Peklaj ve Levpušček, 2006; Özgüngör ve kapıkıran, 2008;Şahin ve Çakar, 2011;Eymur ve Geban, 2011; Singh, 2011; Amrai ve diğ., 2011; Kruskar ve diğ., 2012; Yazıcı ve Altun, 2013; Wood ve Diğ., 2014; Çetin, 2015) çalışmalardır.

Motivasyon ile akademik başarı ilişkisini araştıran araştırmaların birçoğu kimya eğitimi, sınıf öğretmenliği, matematik eğitimi fen bilgisi eğitimi gibi teorik tarafı ağırlıklı olan öğretmen eğitimi bölümleri ile ilişkilidir. Bu araştırmada özellikle güzel sanatlar eğitimi gibi uygulamalı ögretmen yetiştirme eğitiminin diğer araştırmalardan farklı sonuçlar çıkarıp çıkarmayacağına odaklanılmıştır. Güzel sanatlar eğitimi bölümünde eğitim gören öğretmen adaylarının akademik motivasyon düzeylerinin ve akademik başarı ile ilişkisinin çalışılmasının alan yazına katkı sağlayacağı düşünülmektedir. Bu amaçla araştırmada aşağıdaki sorulara cevap bulunmaya çalışılmıştır.

Güzel Sanatlar Eğitimi öğrencilerinin;

1. Resim-İş ve Müzik Eğitimi ana bilim dalı öğrencilerinin akademik motivasyon düzeyleri nedir?

2. Akademik motivasyon düzeylerinde anabilim dalına göre anlamlı fark var midir?

3. Akademik motivasyon düzeylerinde sınıf değişkenine göre anlamlı fark var midir?

3.a. Resim-İş Eğitimi öğrencilerinin akademik motivasyon düzeylerinde sınıf değişkenine göre anlamlı fark var mıdır? 
b. Müzik Eğitimi öğrencilerinin akademik motivasyon düzeylerinde sınıf değişkenine göre anlamlı fark var mıdır?

4.Akademik motivasyon düzeylerinde cinsiyet değişkenine göre anlamlı fark var midir?

5. Akademik motivasyon düzeyleri ile akademik başarıları arasında anlamlı ilişki var mıdır?

\section{Yöntem}

Eğitim Fakültelerinin güzel sanatlar eğitimi bölümlerinde öğrenim gören öğrencilerin akademik motivasyon düzeylerinin ve bu düzeylerin akademik başarı ile ilişkisinin araştırıldığı bu araştırma ilişkisel tarama modeline uygun bir çalışmadır.Tarama modelleri, geçmişte ya da halen varolan bir durumu varolduğu şekliyle betimlemeyi amaçlayan araştırma yaklaşımlarıdır (Karasar, 2005).

\section{Çalışma Grubu}

Araştırma 2015-2016 öğretim yılında Eğitim Fakültesinin resim-iş öğretmenliği (123)müzik öğretmenliği (96) programlarına devam etmekte olan 219 güzel sanatlar eğitimi bölümü öğrencisi ile yürütülmüştür.

\section{Veri Toplama Araçlart}

Bu araştırmada Akademik Motivasyon Ölçeği (AMÖ) kullanılmıştır. Akademik Motivasyon Ölçeği Vallerand ve diğerleri (1992) tarafindan hazırlanmış, Eymur ve Geban'ın (2011) tarafından Türkçe versiyonu oluşturulmuştur. Akademik Motivasyon Ölçeği (AMÖ) içsel motivasyon (öğrenmek için, başarıya doğru ve uyarım yaşama), dışsal motivasyon (farkınavarılmak, içe yansımış ve dış kontrol) ve motivasyonsuzluk alt ölçeklerini içeren 28 tane Likert tarzı sorudan oluşmaktadır.ÖlçeğinCronbach's Alpha güvenirlik katsayılarının her bir alt boyut için güvenilir olduğu araştırmada ifade edilmiştir (Eymur ve Geban, 2011). Bu araştırmada ise, Akademik Motivasyon Ölçeğinin güvenirlik katsayısı 0,75 bulunmuştur.

\section{Verilerin Analizi}

Değişkenlere ilişkin betimsel istatistikler, korelasyon ve varyans analizleri SPSS 22.00 programı kullanılarak .05 anlamlılık düzeyinde test edilmiştir. Öğrencilerin “ Akademik Motivasyon Ölçeği”” 
puanları toplanarak Akademik Motivasyon puanları oluşturulmuştur.. Araştırmada öğrencilerin sınıf değişkenine göre akademik motivasyonpuanları arasındaki fark, verilerin normallik varsayımını sağlayamadığı gerekçesiyle non parametrik testlerden KRUSKAL WALLIS $\mathrm{H}$ testi ile, cinsiyet ve ana bilim dalına göre akademik motivasyon puanları farkını test etmek için ise bağımsız örneklemler testi MANNWHITNEY U testi kullnaılmıştır. Ayrıca akademik motivasyon puanları ile akademik başarı puanları arasındaki korelasyonu test etmek için SPEARMAN'S katsayısı kullanılmıştır.

\section{Bulgular}

\section{Resim-İş Ve Müzik Ĕ̆itimi Ana Bilim Dalı Öğrencilerinin}

\section{Akademik Motivasyon Düzeylerine İlişkin Bulgular}

Araştırmada resim ve müzik öğretmenliği programlarının akademik motivasyon düzeyleri ortalamaları betimsel analiz olarak test edilmiştir. Araştırma bulguları Tablo' 1 ve Tablo 2' de sunulmuştur.

Tablo 1. Resim-İş Eğitimi Ana Bilim Dalı Öğrencilerinin Akademik Motivasyon Düzeylerine İlişsin Betimsel İstatistikler

\begin{tabular}{lrrrr}
\hline \multicolumn{1}{c}{ Resim-İş } & Akad. Motiv. Ort. & İçs. Mot.Ort & Dışs. Mot. Ort. & N \\
\hline 1. Sınıf & 97.09 & 47.87 & 49.21 & 32 \\
2. Sınıf & 100.40 & 49.31 & 51.08 & 35 \\
3.Sınıf & 96.00 & 46.91 & 49.08 & 23 \\
4. Sınıf & 85.03 & 42.69 & 42.33 & 33 \\
\hline Toplam & 94.59 & 46.71 & 47.87 & 123 \\
\hline
\end{tabular}

Tablo 2. Müzik Eğitimi Ana Bilim Dalı Öğrencilerinin Akademik Motivasyon Düzeylerine İlişkin Betimsel İstatistikler

\begin{tabular}{lrrrr}
\hline \multicolumn{1}{c}{ Müzik } & Akad. Motiv. Ort. & İçs. Mot.Ort & Dışs. Mot. Ort. & N \\
\hline 1. Sınıf & 86.06 & 40.87 & 45.18 & 32 \\
2. Sınıf & 94.16 & 47.75 & 46.41 & 24 \\
3.Sınıf & 89.42 & 44.68 & 44.73 & 19 \\
4. Sınıf & 93.00 & 45.52 & 47.47 & 21 \\
\hline Toplam & 90.27 & 44.36 & 45.90 & 96 \\
\hline
\end{tabular}


Tablo 1 ve 2 ' deki sonuçlara bakıldığında resim öğretmenliği programı öğrencilerinin motivasyon ortalamalarının müzik öğretmenliği programı öğrencilerinin motivasyon ortalamalarından daha yüksek olduğu görülmektedir. Betimsel istatistikten ayrıca resim öğretmenliği programının 4. sınıf öğrencilerinin akademik motivasyon puanlarının diğer sinıflara göre düşüş göstermesidir.

2. Güzel Sanatlar Ĕğitimi Öğrencilerinin; Anabilim Dalı Değişkenine Göre Akademik Motivasyon Düzeyleri Farkına İlişkin

\section{Bulgular}

Öğrencilerin Anabilim dalı değişkenine göre akademik motivasyon düzeyleri farkına ilişkin Mann Whitney U testi sonuçları tablo 3' de verilmiştir.

Tablo 3. Güzel Sanatlar Eğitimi Öğrencilerinin Ana Bilim Dalı Değişkenine Göre Akademik Motivasyon Düzeyleri Farkına İlişkin Mann Whitney U Testi Sonuçları

\begin{tabular}{llrr}
\hline \multicolumn{2}{c}{ Akademik Motivasyon } & Sıra Ortalaması & N \\
\hline \multirow{2}{*}{ Ana Bilim Dalı } & Resim- İş Eğitimi & 119.98 & 123 \\
& Müzik Eğitimi & 97.34 & 96 \\
\hline & Toplam & & 97
\end{tabular}

\begin{tabular}{lr}
\hline & Akademik Motivasyon \\
\hline Mann-Whitney U & 4688,500 \\
Wilcoxon W & 9344,500 \\
Z & $-2,614$ \\
\hline P &, 009 \\
\hline
\end{tabular}

Tablo 3'de öğrencilerin ana bilim dallarına göre akademik motivasyon düzeylerinde anlamlı farkın mevcut olduğu bulgusuna ulaş1lmıştır , $U=4688.500$, p<.05.

Tabloda sıra ortalamalarına bakıldığında resim-iş eğitimi anabilim dalı öğrencilerinin akademik motivasyon sıra ortalamalarının (119.98), müzik eğitimi ana bilim dalı öğrencilerinin sıra ortalamalarından (97.34) daha yüksek olduğu görülmektedir. Bu araştırmaya göre re- 
sim-iş eğitimi ana bilim dalı öğrencilerinin akademik motivasyon puanlarının müzik eğitimi ana bilim dalı öğrencilerinin akademik motivasyon puanlarından daha yüksek olduğu söylenebilir.

\section{Güzel Sanatlar Eğitimi Sınıf Değişkenine Göre Akademik Moti-} vasyon Düzeyleri Farkına İlişkin Bulgular

Güzel sanatlar Eğitimi bölümü öğrencilerinin sınıf değişkenine göre akademik motivasyon düzeyleri arasındaki farka ilişkin Kruskal Wallis $\mathrm{H}$ testi sonuçları tablo 4' de verilmiştir.

Tablo 4. Güzel Sanatlar Eğitimi öğrencilerinin sınıf değişkenine göre akademik motivasyon düzeyleri arasındaki Farka İlişkin Kruskal Wallis Testi Sonuçları

\begin{tabular}{|c|c|c|c|c|}
\hline Değişken & Sinıf & & Ort. & $\mathbf{N}$ \\
\hline \multirow{4}{*}{ Akademik Motivasyon } & & 1 & 104,59 & 64 \\
\hline & & 2 & 133,21 & 59 \\
\hline & & 3 & 107,42 & 42 \\
\hline & & 4 & 93,06 & 54 \\
\hline
\end{tabular}

\begin{tabular}{lr}
\hline & Akademik Motivasyon \\
\hline Ki-Kare & 12.326 \\
Df & 3 \\
\hline P & .006 \\
\hline
\end{tabular}

Tablo 4'de görüldüğü gibi güzel sanatlar eğitimi öğrencilerinin devam ettikleri sınıf düzeylerine bağlı olarak akademik motivasyon düzeylerinde anlamlı farkın mevcut olduğu bulgusuna ulaşılmıştır $\mathrm{x}^{2}(\mathrm{sd}=3 . \mathrm{n}=219)=.006 \mathrm{p}<.05$. 
3a. Resim-İş Ĕ̆itimi Ana Bilim Dalı Öğrencilerinin Sınıf Değişkenine Göre Akademik Motivasyon Düzeyleri Farkına İlişkin Bulgular

Tablo 5. Resim-İș Eğitimi Ana Bilim Dalı Öğrencilerinin Sınıf Değişkenine Göre Akademik Motivasyon Düzeyleri Arasındaki Farka İlişkin Kruskal Wallis Testi Sonuçları

\begin{tabular}{|c|c|c|c|}
\hline Değişken & Sinıf & Sira Ortalaması & $\overline{\mathbf{N}}$ \\
\hline \multirow{4}{*}{ Akad. Motiv. } & 1 & 65,64 & 32 \\
\hline & 2 & 77,73 & 35 \\
\hline & 3 & 63,59 & 23 \\
\hline & 4 & 40,68 & 33 \\
\hline \multicolumn{2}{|c|}{ Toplam } & & 123 \\
\hline & Akademik Motivasyon & & \\
\hline Ki-Kare & 19.016 & & \\
\hline Df & 3 & & \\
\hline $\mathbf{P}$ & .000 & & \\
\hline
\end{tabular}

Tablo 5'de görüldüğü gibi resim-iş eğitimi ana bilim dalı öğrencilerinin devam ettikleri sınıf düzeylerine bağlı olarak akademik motivasyon düzeylerinde anlamlı farkın mevcut olduğu bulgusuna ulaşılmıştır x ${ }^{2}(\mathrm{sd}=3 . \mathrm{n}=123)=.000 \mathrm{p}<.05$.

3b. Müzik Ĕğitimi Ana Bilim Dalı Öğrencilerinin Sınıf Değişkenine

Göre Akademik Motivasyon Düzeyleri Farkına İlişsin Bulgular 
Tablo 6. Müzik Eğitimi Ana Bilim Dalı Öğrencilerinin Sınıf Değişkenine Göre Akademik Motivasyon Düzeyleri Arasındaki Farka İlişkin Kruskal Wallis Testi Sonuçları

\begin{tabular}{lrrr}
\hline Değişken & Sınıf & Sıra Ortalaması & N \\
\hline & 1 & 42,63 & 32 \\
Akad. Motiv. & 2 & 55,17 & 24 \\
& 3 & 44,21 & 19 \\
& 4 & 53,71 & 21 \\
\hline & & & 96
\end{tabular}

\begin{tabular}{ll}
\hline & Akademik Motivasyon \\
\hline Ki-Kare & 3.989 \\
Df & 3 \\
\hline P & .263 \\
\hline
\end{tabular}

Tablo 6'da görüldüğü gibi müzik eğitimi ana bilim dalı öğrencilerinin devam ettikleri sınıf düzeylerine bağlı olarak akademik motivasyon düzeylerinde anlamlı farklılık olmadığı görülmüştür $\mathrm{x}^{2}(\mathrm{sd}=3$. $\mathrm{n}=96)=.263 \mathrm{p}>.05$.

4. Güzel Sanatlar Eğitimi Cinsiyet Değişkenine Göre Akademik Motivasyon Düzeyleri Farkına İlişkin Bulgular

Araştırmada öğrencilerin cinsiyete göre akademik motivasyon ölçeği puanları farkını test etmek için non- parametrik testlerden MANN WHITNEY U testi kullanılmış, sonuçları Tablo 7' de sunulmuştur. 
Tablo 7. Güzel Sanatlar Eğitimi öğrencilerinin cinsiyet değişkenine göre akademik motivasyon düzeyleri farkına ilişkin Mann Whitney U testi sonuçları

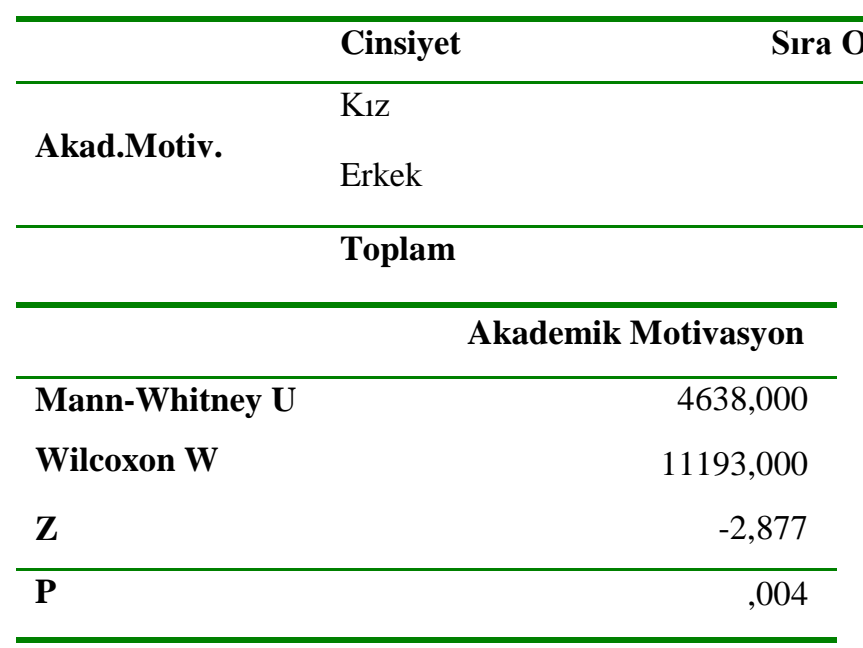

Tablo 7'de sıra ortalamalarına bakıldığında kız öğrencilerin sıra ortalamalarının $(122,83)$, erkek öğrencilere göre $(98,18)$ daha yüksek olduğu anlaşılmaktadır.

Tablo 7'de analiz sonuçları kız öğrencilerle, erkek öğrenciler arasında akademik motivasyon bakımından anlamlı farkın olduğu görülmektedir, $\mathrm{U}=4638.000, \mathrm{p}<.05$.

5. Güzel Sanatlar Eğitimi Akademik Motivasyon Düzeyleri

\section{İle Akademik Başarıları Arasındaki İlişskiye İlişkin Bulgular}

Öğrencilerin akademik motivasyon düzeyleri ile akademik başarıları arasındaki ilişkiye ilişkin Spermans testi sonuçları tablo 8'de verilmiştir. 
Tablo 8.Öğrencilerin akademik motivasyon düzeyleri ile akademik başarıları arasındaki ilişkiye ilişkinSpearmans Katsayıları

\begin{tabular}{cccrr}
\hline & & \multicolumn{2}{c}{ Akad. Başarı } & Mot. Düzeyi \\
\hline Spearman'srho & Akademik Başarı & & 1,000 &, 126 \\
& & P & &, 130 \\
& & N & 219 & 145
\end{tabular}

Tablo 8 incelendiğinde öğrencilerin akademik başarıları ile akademik motivasyon düzeyleri arasında anlamlı bir ilişkinin olmadığı görülmektedir.(rho $=, 126 . \mathrm{p}>.05)$.

\section{Sonuç ve Tartışma}

Araştırmanın bulgularına göre resim öğretmenliği programındaki öğrencilerin akademik motivasyonlarının müzik öğretmenliği programındaki öğrencilere göre daha yüksektir. Araştırma sonucuna benzer bir şekilde, Şahin ve Çakar (2011) araştırmalarında Fen Bilgisi Öğretmenliği programına ve Beden Eğitimi ve Spor Öğretmenliği programına devam eden öğrencilerin ortalama akademik güdülenme düzeylerinin Müzik öğretmenliği programına devam eden öğrencilerin ortalama akademik güdülenme düzeylerinden yüksek olduğunu saptamışlardır. Demir ve Arı' nın araştırmalarında ise, sınıf öğretmenliği programındaki öğretmen adaylarının akademik güdülenme ölçeği aritmetik ortalamalarının okul öncesi öğretmenliği programındaki öğrenim gören öğretmen adaylarının akademik güdülenme ölçeği aritmetik ortalamalarına göre daha yüksek olduğu sonucuna ulaşmışlardır.

Araştırma bulgularından biri de güzel sanatlar eğitimi bölümünde öğrenim göre öğretmen adaylarının sınıf değişkenine göre akademik motivasyonlarında anlamlı farklılıklar olduğudur. Bu farkın hangi ana bilim dalından kaynaklandığı ayrı ayrı incelendiğinde resim öğretmenliği programındaki öğrencilerin sınıf değişkenine göre akademik motivasyonlarının anlamlı farka sahip olduğu (1.sınıf 97.09, 2. sinıf 100.40, 3. sınıf 96.00, 4. sinıf 85.03), bunun yanında müzik öğretmenliği programındaki öğrencilerin akademik motivasyonlarının devam ettikleri sınıf değişkenine göre anlamlı farklılık taşımadığ (1.sinif 86.06, 2. sinif 94.16, 3. sinif 89.42, 4. sinif 93.00), bulgusuna 
ulaşılmıştır. Araştırmada müzik eğitimi ana bilim dalı 2 ve 4 . sınıf öğrencilerinin motivasyon düzeylerinin 1 ve 3. sinıflara göre yüksek olduğu görülmüştür. Küçükosmanoğlu' nun araştırmasında (2015) ise, sınıf değişkeni göz önünde bulundurulduğunda müzik öğretmenliği programı öğrencilerinden 4. sınıf öğrencilerinin içsel ve dişsal motivasyon düzeylerinin diğer sınıf öğrencilerine göre daha düşük olduğu bulgusuna ulaşmıştır. Alemdağ, Öncü, Yılmaz (2014) araştırmalarında sınıf değişkenine göre birinci ve dördüncü sınıfta öğrenim gören kat1lımcıların lehine farka ulaşmışlardır. Akademik Motivasyon Ölçeğinden alınabilecek en yüksek motivasyon puanının 120 olduğu düşünüldüğünde hem resim hem de müzik öğretmenliği programı öğrencilerinin akademik motivasyon puanlarının iyi düzeyde olduğu söylenebilir. Fakat resim öğretmenliği programında 4. sınıf öğrencilerinde yaşanan motivasyon düşüklüğü dikkate değer bir durum olarak araştırılmalıdır.

Araştırmada kız öğrencilerin akademik motivasyonlarının erkek öğrencilere göre anlamlı olarak daha yüksek olduğu bulgusuna ulaşılmıştır. Kız öğrencilerin akademik motivasyonlarının erkek öğrencilere göre yüksek olduğu bulgusuna yapılan başka araştırmalarda da ulaşılmıştır (Eymur ve Geban, 2011; Aktan, 2012; Alemdağ, Öncü, Yılmaz, 2014; ). Buna sonuca karşın bazı araştırmalarda da cinsiyete göre akademik motivasyonun farklılık göstermediği bulgusuna ulaş1lan araştırmalarda mevcuttur (Saracaloğlu, 2008; Şahin ve Çakar, 2011; Demir ve Arı, 2013). Küçükosmanoğlu (2015) müzik öğretmeni adaylarının motivasyon düzeylerini araştırdığı çalışmasında müzik ögretmeni adaylarının cinsiyetlerine göre akademik motivasyon düzeylerinde faklılaşmaolduğunu,erkek öğrencilerin kız öğrencilere göre bilmeye yönelik içsel motivasyon, uyarım yaşamaya yönelik içsel motivasyon ve içe yansıyan dişsal motivasyon düzeylerinin daha yüksek olduğunu, kız öğrencilerin dışsal motivasyon-dış düzenleme düzeyleri erkek ögrencilere göre daha yüksek olduğunu ifade etmiştir. Eymur ve Geban (2011), Spittle, Jackson andCasey (2009)'dan kız öğrencilerinin motivasyonlarının yüksekliği üniversite yıllarında kız öğrencilerin bağlanmışlığının yüksekliğinden kaynaklanabileceğini fakat bunun sadece tahmin olduğuna ilişkin ifadelerini aktarmışlardır.

$\mathrm{Bu}$ araştırmada akademik motivasyon ve akademik başarı arasında anlamlı bir ilişkinin olmadığ 1 bulgusuna ulaşılmıştır. Araştırmanın bulgularını destekleyen araştırmalar mevcuttur (Çetin, 2015). Bunun yanında bu ilişkiyi tespit eden araştırmalara da rastlanmaktadır (Amrai 
ve diğ., 2011; Aktan, 2012; Yazıc1 ve Altun, 2013). Eymur ve Geban (2011) ise, akademik başarı ile sadece iki içsel motivasyon (bilgi ve uyarım yaşama) arasında anlamlı bir ilişki bulmuşlardır. Dışsal motivasyon ile akademik başarı ilişkisine rastlanmamıştır. Buna rağmen Eymur ve Geban (2011) araştırmalarında akademik başarı ve motivasyon ilişkisinin anlaşılmasının, hizmet öncesi öğretmenlerin akademik başarılarını artırmaya yardımcı olabileceğini ifade etmektedir.

Sonuç olarak güzel sanatlar eğitimi bölümü öğrencilerinin akademik motivasyonlarının ölçekten alınabilecek tam puanla kıyaslandığında tatmin edici düzeyde olduğu, cinsiyete göre akademik motivasyon düzeylerinin farklı çalışmalarda farklı sonuçlar verdiği görülmüştür. Araştırmada dikkati çeken resim-iş eğitimi anabilim dalı öğrencilerinin 4. sınıftaki akademik motivasyonlarının anlamlı bir biçimde düşüşüdür. Bu durum KPSS sınav kaygısı ve umutsuzluktan kaynaklanabilir. Akademik başarı ve akademik motivasyon arasında anlamlı bir ilişkinin bulgulanmamamış olması da ayrıca ilginç bir durumdur.

\section{Öneriler}

Güzel sanatlar eğitimi bölümü öğrencilerininmotivasyonunu etkileyen faktörler üzerine nitel yöntemle araştırmalar yapılabilir. Özellikle resim-iş eğitimi anabilim dalı öğrencilerinin 4. sınıfta yaşadığı motivasyon kaybı sorgulanabilir.Güzel sanatlar eğitimi bölümü öğrencileri ile diğer bölümlerin öğrencilerinin akademik motivasyonlarının karşılaştırıldığı araştırmalar gerçekleştirilebilir.

\section{Kaynaklar}

Aktan, S. (2012). Öğrencilerin akademik başarısı, öz düzenleme becerisi, motivasyonu ve ögretmenlerin ögretim stilleri arasındaki ilişki. Yayınlanmamış doktora tezi, Balıkesir Üniversitesi, Balıkesir

Alemdağ, C., Öncü, E., \&Yılmaz, A.K. (2014). Beden eğitimi öğretmeni adaylarının akademik motivasyon ve akademik öz-yeterlikleri.Spor Bilimleri Dergisi. 25(1). 23-35

Amrai, K. Motlagh, S. E.,Zalani, H. A., \&Parhon, H. (2011). Therelationshipbetweenacademicmotivationandacademicachievementstudents. ProcediaSocialandBehavioralSciences. 15. 399-402 
Arıc1, İ. (2007). İlköğretim din kültürü ve ahlak bilgisi dersinde öğrenci başarısını etkileyen faktörler (Ankara örneği). Yayımlanmamış doktora tezi, Ankara Üniversitesi, Ankara.

Çetin,(2015) Predicting academic success from academic motivation and learning approaches in classroom teaching students.Contemporary Issues In Education Research. 8(3). 171-180

Demir, M. K, \&Arı, E. (2013). Öğretmen adaylarının akademik güdülenme düzeylerinin çeşitli değişkenler açısından incelenmesi. Eğitimde Kuram ve Uygula$m a, 9(3), 265-279$.

Eymur, G. \&Geban, Ö. (2011). Kimya Öğretmeni Adaylarının Motivasyon ve Akademik Başarıları Arasındaki İlişkinin İncelenmesi. Eğitim ve Bilim, 36 (161), 246-255

Türk Dil Kurumu (TDK). (2011).Genel Türkçe sözlük. http://www.tdk.gov.tr/index.php?option=com_bts\&arama=kelime\&guid=TD K.GTS.580672244f2118.68133787. 18 Ekim 2011 tarihinde edinilmiştir.

Karagüven, M.H.Ü. (2012). Akademik Motivasyon Ölçeğinin Türkçeye Adaptasyonu. Kuram ve Uygulamada Ĕgitim Bilimleri • EducationalSciences: Theory ve Practice - 12(4) • Güz/Autumn • 2599-2620

Karasar, N. (2005).Bilimsel araştırma yöntemi (15. Bask1). Ankara: Nobel Yayın Dağıtım.

Küçükosmanoğlu, H. O. (2015). müzik öğretmeni adaylarının akademik motivasyonüzeylerinin belirlenmesi üzerine bir çalışma (konya ili örneği). Sanat Ĕgitimi Dergisi. 3(1).1-21

Özgüngör, S.,\&Kapıkıran, Ş. (2008). Güzel sanatlar eğitimi öğrencilerinin öğretmenlik meslek bilgisi derslerine ilişkin motivasyon ve başarı düzeyleri. $P a$ mukkale Üniversitesi Ë̆itim Fakültesi Dergisi. (1) 23.47-60

Peklaj, C. \&Levpušček, M. P. (2006). Students’ motivationandacademicsuccess in relationtothequality of individualandcollaborativeworkduring a course in educationalpsychology. 31. AnnualATEE Conference.

Saracaloğlu, A. S. (2008). Lisanüstü Öğrencilerin Akademik Güdülenme Düzeyleri, Araştırma Kaygıları ve Tutumları ile Araştırma Yeterlikleri Arasındaki İlişki. Yüzüncü Yıl Üniversitesi Eğitim Fakültesi Dergisi, 2, 179-208.

Singh, K. (2011). Study of achievementmotivation in relationtoacademicachievement of students. International Journal of Educational Planning \& Administration. 1(2). 161-171

Spittle, M, Jackson, K, \&Casey, M.(2009). Applying SelfDeterminationTheorytoUnderstandtheMotivationforBecoming a PhysicaIEducationTeacher. TeachingandTeacherEducation:An International Journal of ResearchandStudies, 25(1) , 190-197

Şahin H\&Çakar E. (2011). Eğitim fakültesi öğrencilerinin öğrenme stratejileri ve akademik güdülenme düzeylerinin akademik başarılarına etkisi. Türk Eğitim Bilimleri Dergisi, 9(3), 519-540. 
Vallerand, R.J.,Pelletier, L.G., Blais, M.R., Biere, N.M., Senecal, C., \&Valleries, E.F., (1992). TheAcademicMotivationScale: A measure of intrinsic, extrinsicandamotivation in education. EducationalPsychologicalMeasurement, 52, 1003-1017.

Wood, J. L. (2014). Motivationalfactorsforacademicsuccess: perspectives of africanamericanmales in thecommunitycollage. TheNationalJournal of Urban Education\&Practice. 7(3). 247-265

Yazıc1, H. \&Altun, F. (2013). Üniversite öğrencilerinin içsel ve dışsal motivasyon kaynakları ile akademik başarıları arasındaki ilişki.International Journal of SocialScience. 6(6). 1241-1252

Yılmaz, M., (2010).. "Sanat Eğitiminde Motivasyon, Sanat Eğitiminde Kopya ve Taklit, Görsel sanatlarda Teknik ve Yöntemler"(ed. Kazım Artut). (s.193297). Güzel Sanatlar Eğitiminde Özel Öğretim Yöntemleri. Anı Yay. Ankara,

\section{Extended Summary}

Teachers, who are the practitioners in the process of education policies, undertake the most important duty in the necessity and desire of educating qualified people. The achievement of this duty depends on the success of teacher training institutions and students who are studying in these institutions. In this sense, it is important to study on the factors affecting students' success and take precautions increasing the success. As it is stated in many studies, motivation is among the factors that affect students' success. Motivation, according to Turkish Language Association, means prompting, making someone move, driving force and inner power directing to move and it is also defined as motivation of someone for a target. Motivation has been studied with its many different angles in education. These studies are generally related to the effects of motivation on academic performance and success. Many of the studies that examine the relation between motivation and academic success are related to theory weighted departments such as chemistry teaching, primary school teaching, mathematics teaching and science teaching. The focal point of this study is whether different results may be found by examining the students' academic motivation who are studying in department of fine arts - an applied field.

\section{Aim of the Study:}

In this study it is aimed to examine the academic motivation level differences of Fine Arts Department students from Faculty of Education according to certain variables (department, class, sex) and also, the relationship between their academic motivation and their academic successes.

\section{Method:}

In the study, one of the quantitive research methods, relational screening model, was used. The study was carried out with 219 students (Art Teaching 123, Music Teaching 96) who study at Fine Arts Department of Faculty of Education. 
Academic motivation scale (AMS) including the dimensions as amotivation, inner motivation, exterior motivation was applied to study group. Academic motivation scale was prepared by Vallerand et al. (1992) and its Turkish version was formed by Eymur and Geban (2011). Academic motivation scale (AMS) consists of 28 Likert type questions that include inner motivation, exterior motivation and amotivation subscales.

Data of the study were tested in SPSS. 22 program with 0.5 level of significance. Non-parametric tests were preferred in the analysis of the data. Mann Whitney U test was applied in order to compare academic motivation according to department and gender variables and Kruskal Wallis $\mathrm{H}$ test was used to test the academic motivation difference according to grade. In the study, the relation between academic motivation and academic success was tested via Sperman correlation test.

\section{Findings}

According to findings there are significant differences between arts teaching candidates and music teaching candidates in terms of their academic motivation levels. This difference is in favor of arts teaching. Significant difference was also found between teacher candidates' academic motivation levels according to gender and grade variables. In the study it was also concluded that girls' academic motivation levels are higher than boys' and academic motivation level of students only in arts teaching department vary significantly according to grade variables. Especially the decrease in final year students' motivation level is noteworthy. According to the findings of the study there is not a meaningful relationship between academic motivation and academic success.

\section{Discussion:}

According to the findings of the study, the academic motivations of students in Art Teaching Department are higher than the ones in Music Teaching department. Even if in other studies, the motivation levels of certain departments (Science, Physical Training and Sports, Primary School Teaching) seem higher than others, comparisons with departments that feature applied trainings are not common. In one study, it is found that the academic motivations of students in Science, Physical Training and Sports Teaching Departments were higher than students in Music Teaching. In the study, according to grade variables, there are not significant differences in Music Teaching Department, there is however, a significant decrease in the motivations of $4^{\text {th }}$ grade students in Art Teaching Department. Different results were found to occur in other studies. It is evaluated to be satisfactory that the motivation levels are in good state in the study.

It is very common finding in many studies that girls' academic motivations are higher than boys'. However, there are also some studies in which the findings were found to be the reverse of this situation. In this study, the obtained findings showed that there was no significant relation between academic motivation and academic success. Although there are some studies supporting these findings, in some other studies the relation was found. 
M.Yılmaz,O.Taşkesen.../Ë̈Ë̆̈itimFakültesiDergisi,18-2(2016),1056-1072

Consequently, it was found that fine arts education students' academic motivations was on the satisfactory level when compared to total point of the scale and their academic motivation levels according to gender vary in different studies. Remarkable point in the study is the significant decrease in $4^{\text {th }}$ grade art teaching department students' academic motivation. This can stem from Public Personnel Selection Exam anxiety and hopelessness. It is interesting that there is no relation between academic motivation and academic success but this situation is common in the studies of related field.

\section{Result:}

As a result it can be concluded that fine arts department students' academic motivation level is satisfying in general. As already seen in my studies, it is an expected situation that girls' academic motivation level is higher than boys'. The decrease in $4^{\text {th }}$ grade art teaching department students' academic motivation can stem from exam anxiety and hopelessness and not experiencing the same decrease in $4^{\text {th }}$ grade of music teaching program can be explained with the fact that art teaching students' academic motivation is significantly higher than music teaching according to department variable. In the study, it was also inferred that academic motivation of art teaching candidates' is higher than music teaching candidates' and this situation can be related to the appointment percentage to public services and difference in their education.

\section{Suggestions:}

As a result of the study, it is suggested that carrying out the studies with qualitative methods gives more concrete results when fine arts training department students' academic motivation is compared with students from other departments, especially the decrease in $4^{\text {th }}$ grade art teaching department students' academic motivation should be questioned with qualitative methods. 